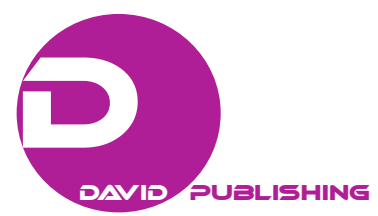

\title{
Educational Technology and Mass Communication
}

\author{
Owuamanam Catherine Nkechinyere \\ National Institute for Nigeria Languages, Aba-Abia, Nigeria
}

\begin{abstract}
Communication is as old as man. It is the basis of social interactions and the lifeblood of human societies. There is hardly any society or sovereign state that can function properly today without the mass media. Of all earth's creature, humans are the only ones not content simply to communicate at interpersonal level. They want to know what is happening in other far places, lands, and culture. In view of the above, this paper examines the effect of educational technology in mass communication. This study, however, explores the concepts of educational technology, mass media, and mass communications, functions and consequences of mass media in mass communication. Finally, some recommendations were made for the reduction of the consequences.
\end{abstract}

Keywords: educational technology, media, mass media, communication, mass communication

\section{Introduction}

Educational technology is an integrated and systematic way of designing, planning, implementing, and evaluating total process of teaching and learning in terms of specific objectives, research, and information on human learning and the process of communication (Onyejemezi, 1996). The communication process involves all acts of transmitting messages to channels, which link people to the languages, and symbolic codes, which are used to transmit messages, the means by which messages are received and stored and the rules, customs, and convention which define and regulate human relationships (Daramola, 2005).

Communication is the transfer of a message to another party, so that it can be understood and acted upon. It includes all the ways and manner through which we can let other people know and share our thoughts, feelings, experiences, and knowledge (Federal Ministry of Education [FME], 2007). Communication takes place at two main levels, namely: interpersonal communication levels and mass communication levels. Interpersonal communication is person-to-person communication in which the people interacting are physically present. Mass communication system is impersonal. The people communicating may not necessarily see or know themselves. But the greater number of people is reached through the mass communication resources. Such resources are called "mass media” (FME, 2007).

Mass media is described as a means of communication that operate on a large scale, reaching and involving virtually everyone in a society to a greater or lesser degree (Daramola, 2005). It also refers to a number of media established and familiar, such as newspaper, magazines, film, radio, television, phonograph (recorded music), computer, and the Internet.

The creation and multiplication of these technical means of communication have greatly enhanced and freed the communication process from the limitation of time and space. Mass media provide people with

\footnotetext{
Owuamanam Catherine Nkechinyere, Ph.D., lecturer, School of Education, National Institute for Nigeria Languages.
} 
information they need to formulate their own ideas and can stimulate them by presenting the ideas of others. It provides reliefs from boredom, stimulates our emotions, helps fill our leisure time, keeps us company, and exposes us to experience and events that we could not attend in person (Daramola, 2005).

Much as mass media enhances the process of mass communication, it also influences mass communication negatively. For example, mass surveillance can result to needless anxiety and have instigated, supported, and justified wars. Also, entertainment on media threatens allegiance to the state, corrupt morals and disables the natural good taste of the public (Daramola, 2005). It is against this background that the researcher examines the effects of mass media in mass communication.

\section{Theoretical Framework}

The theoretical base of this work stems from the libertarian theory of the press. Siebert Fred is cited as foundational influence on the development of this perspective. The theory espouses that the press must have unfettered freedom to assist men in search of truth. The truth is to be discovered through reason but in this regard man must have free access to information and ideas. Out of the staple the press serves him, he can by employing his intellect, distinguish truth from falsehood.

According to the libertarian theory, free expression carries built-in correctives and as such few restrictions are permitted on what man may speak and write. The theory opines that the great majority of men are moral creatures who will use their freedom in a responsible way in an honest desire to find truth. The libertarian theory opposes censorship before publication.

Siebert (as cited in Daramola, 2005) stated that the "mass media in the view of the libertarian is meant to inform and to entertain their audience". He went further to say that the understanding of purpose of the media is to help discover the truth, to assist in the successful working of self-government by presenting all manner of evidence and opinions as the basis for political and social decisions and to safeguard all liberties by providing a check on government.

In a nutshell, the libertarian theory of the press opines that man is rational, and as a result, he is imbued with the ability to find truth and to distinguish right from wrong by the power of his reason and the dictates of his conscience. The theory believes in self-righting process in a free market place of ideas and opinion. That is, truth will win out in any free and open encounter of ideas, grant all men the freedom to express themselves in the clash of ideas that ensues, the true and sound will triumph over falsehood.

\section{Educational Technology}

Education is a process of preparing the individual for self-preservation or survival by enabling him to be able to grow up as a healthy individual, capable of making proper use of his leisure, living as an effective citizen concerned with the promotion of common welfare and maintaining character (Onwuka, 1996). Technology on its own is the systematic application of scientific or other organized knowledge to practical tasks (Schneider, 2015).

Educational technology is a wide field. It has been defined and explained by its practitioners. According to Onyejemezi (1996), educational technology:

Embraces educational objectives, curriculum content, means of learning and the evaluation and modification of the learning system, with a view to improving effectiveness. It is concerned with the whole process of acquiring knowledge. This process involves the learners, the content, the teacher, methods, resource materials as well as other educating agents. 
Educational technology emphasizes new developments in teaching and learning, course content and the fullest use of central services concerned with the application of instructional materials and devices.

Explaining further, she states that educational technology is broadly conceptualized with the following as parts of the whole:

1. Technology (resources, materials, and devices) used in education and training including the management of the educational technology resources;

2. An objective oriented approach to the solution of educational problem-A technique derived from programmed learning;

3. A systematic approach to course and/or instructional materials development and evaluation;

4. A systematic management of teaching and learning.

Association for Educational Communication and Technology (as cited in Wikipedia, 2016) defines educational technology as "the study and ethical practice of facilitating learning and improving performance by creating, using and managing appropriate technological processes and resources”. Educational technology refers to the use of both physical hardware and educational theoretic. It encompasses several domains, including learning theory, computer-based training, online learning, and m-learning (Wikipedia, 2016). Accordingly, there are several discrete aspects to describing the intellectual and technical development of educational technology:

1. Educational technology as the theory and practice of educational approaches to learning;

2. Educational technology as technological tools and media that assist in the communication of knowledge, its development and exchange;

3. Educational technology for learning management systems (LMS), such as tools for student, curriculum management, and education management information systems (EMIS);

4. Educational technology itself as an educational subject: such courses may be called "Computer Studies" or "Information and Communication Technology (ITC)” (Wikipedia, 2016).

Similarly, Anderson (2003) defined educational technology as "a complex integrated process involving people, procedures, ideas, devices, and organization for analyzing problems and devising, implementing, evaluating, and managing solutions to those problems involved in all aspects of human learning”. It is a systematic iterative process for designing instruction or training used to improve performance (Collins, 1992). However, Selwyn (2011) stated that educational technology is "a systematic way of carrying out and evaluating a total process of teaching and learning in terms of specific objectives, based on research in human and non-human resources to bring about a more effective instruction in a given environment”.

Educational technology encompasses e-learning, instructional technology, information and communication technology (ICT) in education, learning technology, multimedia learning, technology-enhanced learning (TEL), computer-based instruction (CBI), computer managed instruction (CMI), computer-based training (CBT), computer-assisted instruction or computer-aided instruction (CAI), Internet-based training (IBT), flexible learning, Web-based training (WBT), online education, digital educational collaboration, distributed learning, computer-mediated communication, cyber-learning, multi-modal instruction, virtual education, personal learning environment, networked learning, virtual learning environments (VLE) (which are also called “learning platforms”), m-learning, ubiquitous learning, and digital education (Selwyn, 2011).

Finally, educational technology is both product and processes. The products must be fully and properly integrated into the processes in order to achieve objectives of instruction or overall educational objectives. 


\section{Mass Media}

When people communicate with one another, they do so by means of a medium, some device or process through which they convey information. The English language is a medium, so is a smile, a smoke signal, a number, anything that people use to transfer information or to represent information is a medium of communication (Daramola, 2005). Media is the plural of medium, which means a channel or vehicle through which something is carried or transmitted (Ademoyin, 1991). Media differ from one another, first of all with respect to the kinds of information they convey.

Numbers, for instance, convey information about quantity but not quality, neither prose nor poetry can express the information transmitted by a shrug of the shoulders. Media also differ with respect to what modes of perception and thought and what types of personal experience and social interaction they make possible for people. This is because each medium transmit only a distinctive, limited range of messages (Daramola, 2005).

According to McQuail (as cited in Dramola, 2005), mass media is described "as a means of communication that operate on a large scale, reaching and involving virtually everyone in a society to a greater or lesser degree”. It refers to a number of media that are now long established and familiar, such as newspaper, magazines, film, radio, television, and the phonograph (recorded music). In other words, mass media are channels of communication in a modern society, primarily the print and electronic media.

Mass media means the various media, through which individuals are enlightened, educated, entertained, mobilized, and persuaded (Owuamanam, 2016). According to Barbara (2007), mass media could be written, broadcast, or spoken, and it is aimed at reaching a large audience. The advent of mass media which were not based on print culture opened up new worlds to even more people. Mass media operating with pictures and sounds, most typically film and television, gave really large parts of the population access to media culture.

Today, electronic media provide access to information and entertainment to all parts of the population (Njemanze \& Ononiwu, 2015). Mass media are the organized means for communication openly and at a distance to many receivers within a short space of time. The mass media, like spoken word and the raised eyebrow are simply aspects of human communication. They are technical extensions of speech and gesture. In fact, communication media extend gesture (Daramola, 2005).

The mass media-television, radio, newspapers, magazines, books, and movies are impersonal communication sources and they reach large audiences (Daramola, 2005). The primary function of mass media systems is to provide information to several millions of people. The fact that they reach a large number of people far beyond the imagination and reach of human voice, the mass media are extremely influential.

Each of the media is presumed to affect perceptions and behaviour in a distinctive way. They can affect the society and society can also affect the media. It must, however, be noted that mass media are the uniquely modern means of mass communication and much of their importance lies in the fact that they are a major cause of whatever modes of perception, thought, public discourse, and political action (Daramola, 2005). Because of their size and the large number of people they reach, the mass media have tremendous impact on mass communication.

Finally, mass media is communication-whether written, broadcast, or spoken-that reaches a large audience. This includes television, radio, advertising, movies, the Internet, newspapers, magazines, and so forth (Houghton, 2016). 


\section{Characteristics of Mass Media}

Mass media have the following characteristics:

1. Mass media are media designed for, distributed to, and consumed by mass audience. The mass audiences are very large, either in terms of number or proportion of total population and the audience exist in large, heterogonous societies either industrial or transitional societies like ours in Nigeria.

2. Mass media are big business employing millions of people and making billions of dollars as profit. In Nigeria, the mass media are striving hard to stand in business despite stringent economic policies and high tariff over importation of newsprint, chemicals, and further devaluation of local currency (Naira). However, as big businesses, their news and entertainment are produced by bureaucracies following routine procedures. They work towards making profits and still operate within commercial constraints.

3. Mass media are sole disseminators of news (defined as factual, current, and verifiable information about recent events). Mass media also disseminate other sorts of information-frictional stories, political advocacy, and strictly utilitarian information like recipes.

4. Mass media are characterized by speed with which they gather information and frequency with which they distribute it. Media producing organizations are continuously gathering information and are instantaneous communication with their sources of information. They package and distribute such information at least once each day. The speed and rhythm of this ongoing process of gathering and distributing information especially news, sharply differentiate mass media from other media and exert enormous influence on the character of their messages.

5. Mass media are all 20th-century phenomena. In other words, they all developed and attained maturity during roughly the same period in response to the same circumstances and in pursuit of the same purposes. Each is said to incorporate modes of communication (typography, language, music, scenery, and so on), some ancient, all originating in deferent periods. Except for the newspapers which came much earlier, the mass media are, however, regarded as 20th-century, phenomena serving all nation-states of the world today (Daramola, 2005).

\section{Mass Communication}

Communication is basic to life: Its role in human society is underscored in the fact that no meaningful development can take place without it (Yaaka, 2017). It is the process of sending and receiving information (messages). Communication includes all the ways and manner through which we can let other people know and share our thought, feelings, experiences, and knowledge (FME, 2007).

According to Yaaka (2017), communication is "any means by which a thought is transferred from one person to another". It is a process by which meaning is assigned and conveyed in an attempt to create shared understanding. This process which requires a vast repertoire of skills in interpersonal processing, listening, observing, speaking, questioning, analyzing, gestures, and evaluating enables collaboration and cooperation (Wikipedia, 2016).

Communication is the transfer of a message to another party, so that it can be understood and acted upon (Daramola, 2005). Communication can be seen as processes of information transmission with three levels of semiotic rules:

(a) pragmatic (concerned with the relations between signs/expressions and their users); 
(b) semantic (study of relationships between signs and symbols and what they represent);

(c) syntactic (formal properties of signs and symbols).

Therefore, communication is social interaction where at least two interacting agents share a common set of semiotic rules (Wikipedia, 2016). The communication process involves all acts of transmitting messages to channels which link people to the languages and symbolic codes which are used to transmit messages, the means by which messages are received and stored, and the rules, customs, and convention, which define and regulate human relationship.

Communication takes place at different levels. Sometimes, the sender and the receiver may even be the same person. But most of the time, we communicate with others. As a result, we communicate at two main levels, namely: interpersonal and mass communication levels. Interpersonal communication is person-to-person communication, in which the people interacting are physically present.

The process of interpersonal communication involves participants negotiating their role in this process, whether consciously or unconsciously. Senders and receivers are of course vital in communication. In face-to-face communication, the roles of the sender and receiver are not distinct as both parties communicate with each other, even if in very subtle ways, such as through eye-contact and general body language. There are many other subtle ways that we communicate (perhaps even unintentionally) with others, for example, the tone of our voice can give clues to our mood or emotional state, whilst hand signals or gesture can add to a spoken message (Twitter, 2016).

Mass communication is a situation whereby so many people are target audience of the speaker. As a result of the population of the audience, the speaker may resort to using such mass media like the radio and the television to reach out to the audience in different locations simultaneously. Other mass media include the newspapers, magazines, sound film, and the Internet (Yaaka, 2017). According to FME (2007), the mass communication system is "impersonal". The people communicating may not necessarily see or know themselves. But greater numbers of people are reached through the mass communication system than will ever be the case with the inter-personal communication.

Ike (2006) called it mass media communication. According to him, the communicator sometimes cannot maintain eye-contact with the audience(s), because they are separated in time and space. The only way possible of reaching out to the audience(s) is usually through a medium or media of mass communication, which include the radio, television, telegrams, telephone, fax, Internet, facsimile, and newspapers. Of all earth's creatures, humans are the only ones not content simply to communicate at interpersonal level. The quest to communicate with people at far places led to the development of modern means of communication. This technical or mediated means include telegraphy, printing, broadcasting, and film. They are the secondary means of communication (Daramola, 2005). Mass communication, therefore, is an organizational means for communicating openly and at a distance to many receivers within a short space of time through the technical and mediated means of communication.

\section{Effects of Mass Media in Mass Communication}

There is hardly any society or sovereign state that can function properly today without mass media. Everywhere, mass media inform the public of important affairs. They transmit government policies and actions for the information of the people. They also provide information on which many readers form opinions. As a matter of fact, mass media have shaped culture, influenced politics, played an important role in business and 
affected the daily lives of millions in the past few centuries (Daramola, 2005). The mass media are useful and also dysfunctional to the society.

Mass media have the following functions and consequences in mass communication:

Surveillance of the environment. Surveillance refers to news and information role of mass media. From 1859, the mass media have taken over the function of sentinels and watchers. Correspondents within and outside Nigeria, especially of the wire services and media giants, such as Cable News Network (CNN) gather information for us that we could not get by ourselves (Daramola, 2005). Dominick (1996) said that these information are funneled back to mass media organizations that in turn produce a radio or television newscast or newspapers or magazines. Today, Nigeria has as many as 100 newspapers either as Private, State government, or Federal government owned and each of the 36 states in Nigeria has a radio and television station each in addition to the number of Federal government owned radio and television stations (Daramola, 2005).

There is no gainsaying that the role of surveillance being played today can no longer be played by individuals because of the size, population, and the complexity of the society. The surveillance function is divided into two (Dominick, 1996). There are warning or beware surveillance and instrumental surveillance. Warning surveillance occurs when the newspaper, radio, or television inform people about imminent threats, erupting volcano, drought, or other disaster, such as the Tsunami flood of December, 2004, depressed economic conditions, possible attacks in the Bakassi Peninsula and insurgence in the Niger Delta area.

Instrumental surveillance is concerned with the transmission of news and information that is beneficial to the people, such as news of new film or video film in town, new fashion in vogue, new products, recipes, and stock market prices. One of the beauties of the modern mass media especially the electronic is that news travels faster than imagined in the traditional setting. An event can be relayed live almost simultaneously as it is happening. A good example was what happened in 1998 when the Nigerian Head of State, General Sani Abacha died. In less than 24 hours, the news had been broadcast, first by Channel Television Station in Lagos and later by others (Dominick, 1996). Events at the national and international scenes are beamed to us on daily basis.

As information media, radio, and television are primarily useful in signalizing events, making the immediate and usually sketchy reports that announce a happening. Newspapers place more emphases on information. Hence, the abundance of news stories, interpretative articles and editorials, photographs, and other materials in their content. Newspapers also advise, guide, persuade, and influence their readers by means of advertisements and editorials (Daramola, 2005).

Consequences of surveillance. Much as news travels faster in the mass media much more than that of town criers, the speeds leads to problems. The problems take the shape of inaccuracies and distortions of news, because mass communications relay information without taking the pains to check their facts as required by the Code of Conduct of Journalism. For example, a report said that Israel had mounted a retaliatory raid against Iraq whereas no such thing happened (Dominick, 1996).

Also, mass media surveillance can result in needless anxiety. In 1993, the Nigerian media reported a likely breakup of the country following the annulment of the presidential election believed to have been won by Social Democratic Party' candidate, Chief M. K. O. Abiola of Yoruba tribe. The print media coined many words and beat drums of war. The fear created then led many people of other tribes particularly the easterners to flee the North and South West for their home land for possible reprisal attacks. The irony of it was that many of the people perished in automobile accident on their way (Daramola, 2005). 
Historians equally say that newspapers have instigated, supported, and justified wars. They cited the 1870-1871 Franco-Prussian War, the Spanish-American War of 1898, and the Vietnam War of 1955-1975 (Daramola, 2005). Mass media can also raise false hopes. Sometimes, in the year 2003, it was widely reported that a possible cure for Acquired Immune Deficiency Syndrome (AIDS) had been discovered in Nigeria. A Nigerian medical doctor, Dr. Jeremiah Abalaka was said to have developed a curative drug. The news media gave so much publicity to this story which had given many Nigerians succor and hope of a cure to the dreaded disease. The Federal government later debunked the claim as lacking scientific proof (Dominick, 1996).

Mass media can do and make a less important person become important by constant coverage of such a person. That is mass media can make a person a celebrity. The Nigeria mass media made General Ibrahim Badamosi Banbangida (IBB) (1985-1993), former military president of Nigeria popular. In 1993, when the general appeared to the vacillating on the handling over plan to a democratically elected government, the media began a campaign of calumny against him. He was no longer the fine IBB of Yesteryears. He immediately became to the media an evil genius and dictator (Daramola, 2005).

\section{Interpretation}

The mass media do not supply just facts and data but provide detailed analysis on information already relayed. The mass media provide information on the ultimate meaning and significance of those events. Interpretation functions are performed by the mass media through articles, editorials, features, and cartoons to shed more light on issues and discussion on radio and television about political, economical, or social events. Our attitudes and opinions about political figures for instance are often influenced by the impression we receive from the mass media (Daramola, 2005).

Apart from straightjacket news in newspapers and magazines, a great deal of information in the print media is devoted to interpretation. They clarify, explain, and place facts in a meaningful context. As a matter of fact, these are the raisons d'être of thousands of articles and editorials in newspapers and magazines. Magazine's interpretative function is greater (Daramola, 2005). Magazine places events in a national perspective. Magazines are chiefly devoted to fleshing out the information and carefully analyzing stories treated in passing in the broadcast media and newspaper. Beside editorials and articles, editorial cartoons are another popular means of interpreting issues. Some newspapers and magazines review restaurants, cars, architecture, and even religious services.

\section{Consequences of Interpretation}

A negative aspect of this function is that any criticism of an individual, organization, or group may also affect the views of others about the mass medium involve. Sometimes, in the year 2004, the police discovered a shrine in Okija, a town in Anambra state of Nigeria where human beings were sacrificed to a deity. The news was regularly splashed on the pages of newspaper that it becomes agenda of discussion for a long time. Notwithstanding the enormity of this act, people of Igbo extraction in the Eastern part of Nigeria began to view the media publicity as people who did not understand the culture of Igbo people and for that stigmatized the media as Southwest media (Daramola, 2005). Another negative aspect of this function is that an individual may find it difficult to form his own opinion on any issue. Where such a person relies heavily on media messages, he/she soon loses his/her critical thinking ability.

\section{Linkage}

By linkage, mass media are able to join together by interpersonal channels different elements of society 
that are not directly connected (Dominick, 1996). Mass communication attempts to link the needs of buyers with the products of sellers. Effort by the Comet newspaper in Nigeria to raise money for the Tsunami 2004 survivors in Asia in January 2005 is another example of this linkage function. The needs of the survivors of the wave matched with the desires of others who wished to see the homeless survivors back to normal condition (Daramola, 2005).

Media usage reached record levels during the war as people turned to television, radio, newspaper, and magazines to read and hear about the latest war news. The same thing happened towards the end of year 2004 when Nigerian newspaper began to carry reports of deliberate killing of people in Darfur region in Sudan. The news reports linked Nigeria to the region to the extent that Nigerians began to call for end to the genocide. The call of the media attracted President Olusegun Obasanjo, who incidentally is the chairman of African Union (AU). The president brokered peace and got the matter resolved in a round table (Dominick, 1996).

The various message boards on the Internet or commercial online companies, such as America online and prodigy have all served the purpose of linkage. Interested members can open the Internet and also leave message for others to see (Dominick, 1996). The mass communication through the help of mass media can also create new social groups by linking members of society that were not previously recognized with others that have similar interest. This is "public-making” ability of the mass media (Dominick, 1996).

The linkage function of mass media is also noted at another level. Certain fashion or dresses put on by people are done to advertise feelings, so that others with similar concerns might "link up" with them. People who wear T-shirts and ladies who wear trousers, miniskirts, "jumper”, and "body hog” are believed to have copied this dressing from foreign films watched on television. Such ladies have been linked up on the media (Dominick, 1996).

\section{Consequences of Linkage}

The societal groups can be mobilized quickly. In 1983, Ondo State radio was used to incite the people against the election result that nullified the incumbent governor. The protest match led to the killing, arson, and destruction of life and properties of political opponents in Akure. Similarly, persons with anti-social interests can be linked easily. Women and girls of antisocial interests on television copied the type of dressing mentioned earlier, which is in vogue in Nigeria today. Some ladies are almost appearing naked and some are known to have enticed men with this type of dress. Media attention to violent firms, terrorists, and other extremist groups might prompt others in the same direction too (Dominick, 1996).

\section{Transmission to Cultural Heritage}

One of the functions of mass communication is the transmission of cultural heritage from one generation to the next. This refers to the mass media's ability to communicate norms, rules, and values of a society. The mass media provide cultural guidelines and help teach the citizens of a society how to behave and what is expected of them through various programmes that are put before the public (Egbon, 1995).

As a teacher, mass communication uses mass media to pass the societal heritage. The mass media present portrayals of our society and by watching, listing, and reading, we learn how people are supposed to act and what values are important or permissive. Most of the time, the mass media especially television, show men and women, who dress in the local attire, appearing decent, cheerful, and colourful. Sometimes, certain drama may be shown where children clearly demonstrate that they have etiquette in form of greetings and the way they attend to visitors, elders, and the type of dressing they put on (Egbon, 1995). 
Mass media transact values by enforcing societal norms. Media coverage can ensure that acceptable values of the society are highlighted and upheld by what they choose to emphasize. Not quite long, a mass medium showed a marriage ceremony held in a church where the church minister protested the way and manner the bride dressed to the altar half-naked and warned that such so-called civilized way of dressing will not be condoned in the house of God (Daramola, 2005). This is in consonance with the belief that the media present and clarify the goals and values of society.

\section{Consequences of Transmission of Cultural Heritage}

Violent acts of children have been attributed to violent films, movies, and programmes watched on television. There is the belief that such films depicting violence could prompt youngsters to want to believe that what they watched on the television is real. In 1985, the government of General Muhammed Buhari banned foreign films that tended towards violence on the Nigerian television states (Daramola, 2005).

\section{Entertainment}

The entertainment function refers to the communicative acts primarily intended for amusement irrespective of any instrumental effects they might have. Apart from information and news-proving function of mass communication among other things, mass media serve the purpose, which the storytellers and jesters of yesteryears perform. It refers to the media's ability to present messages that provide escapism and relaxation.

Motion picture, sound recording, and some books are devoted primarily to entertainment. Similarly, newspapers include comics, word puzzles, games, advice, gossip, humour, and general entertainment feature in their content to amuse readers or to task the brain of readers in solving crossword puzzles. Television ranks the highest in terms of entertainment media. In the evening, television entertains viewers with drama, play, films with which one is able to relax the tension of the day. Some of these dramas entertain as well as teach new value system. Newspapers and magazines are more informative in nature. Magazines are more into serious information. Movie making and broadcasting are commonly referred to as entertainment industries, amusing the public is their acknowledged primary function. Through entertainment, the media are capable of creating folk heroes. Entertainment is necessary to provide the relief to enable human beings to face the demands of life in general. People need to relax. Television is a medium of escape (Daramola, 2005).

\section{Consequences of Entertainment}

There is great fear that entertainment could lead to corruption of mind at least going by the violent films on the television. Many also believe that entertainment on the media threatens allegiance to the state, corrupt morals and disables the natural good taste of the public. Critics have, however, argued that entertainment provided by the mass media encourage passivity on the part of audience.

The argument is that rather than allowing people to develop the habit of entertaining themselves, the mass media make them on lookers or spectators without allowing participation. Rather than learn to act drama, narrate stories or engage in moonlight folklore, many of us now prefer to listen a record of someone else playing or flick on the TV set, watch entertainment, which does not require any effort on our part. As a result, critics say the mass media will eventually turn modern society to societies of watchers and listeners instead of doers (Daramola, 2005).

\section{Conclusions}

Educational technology is an integrated and systematic way of designing, planning, implementing, and 
evaluating total process of teaching and learning in terms of specific objectives, research, and information on human learning and the process of communication. Communication is the transfer of a message to another party, so that it can be understood and acted upon. Communication takes place at two main levels, namely: interpersonal and mass communication levels.

Interpersonal communication is person-to-person communication in which the people interacting are physically present. Mass communication is impersonal. But greater number of people is reached through mass media. It is against this background that this paper examined the functions and consequences of mass media in mass communication. The theoretical base of this work stems from libertarian theory of the press. The paper also examined the concepts of educational technology, mass media, and mass communication and the functions and consequences of mass media in mass communication.

The functions of mass media in mass communication include: surveillance of the environment, interpretation, linkage, and transmission of cultural heritage. The consequences are as follows:

1. Much as news travels faster in the mass media much more than that of town criers, the speed leads to problems;

2. Newspapers have instigated, supported, and justified war;

3. Mass media can also raise false hopes;

4. Mass media can make a person a celebrity;

5. Any criticism of an individual, organization, or group may affect the views of others about the mass medium involved;

6. Individual may find it difficult to form his/her own opinion on any issue;

7. The societal groups can be mobilized quickly;

8. Person with anti social interests can be linked easily;

9. Violet acts of children have been attributed to violet films, movies, and programmes watched;

10. And lastly, entertainment function of the mass media could lead to corruption of the mind.

\section{Recommendation}

Based on the consequences of mass media, the following recommendations were made:

1. Mass communication should take the pains to check their facts as required by the code of Conduct of Journalism. This will prevent inaccuracies and distortions of news. Misrepresentation in the news is often the result of hasty reporting or misinformation.

2. People should form it as habit to verify information they read in the newspaper, heard over the air and seen on the screen by themselves. They should not take for granted information from these mass media without bothering about the veracity and authenticity of such reports.

3. People should be allowed to develop the habit of entertaining themselves, learn to act drama, narrate stories, and engage in moonlight folklore.

4. The Federal government as a matter of necessity should ban the importation of violet films, movies, and programmes from foreign countries. There is belief that such films depicting violence could prompt youngsters to believe that what they watched on the tube is real.

5. People should be encouraged to use their critical thinking ability in dealing with any information from any mass medium. Also, any person with contrary view outside what any medium publishes should be respected and not considered as not be abreast with the issue of the moment. 


\section{References}

Ademoyin, J. N. (1991). Introduction to educational technology (p. 70). Lagos: John Lad-Publishers Ltd.

Anderson, T. (2003). Models of interaction in distance education: Recent developments and research questions. Retrieved 2015, from http://edutechwiki-unigech/en/educationaltechnology

Babara, G. (2007). The role of media in the developing literacies and cultural techniques. Digital Competence, 2, 76-78.

Collins, A. (1992). Towards a design in science of education. In E. Scarilon and T. O. Shea (Eds.), New directions in educational technology. Berlin: Springer Verlag.

Daramola, I. (2005). Mass media and society (pp. 157-205). Lagos: Rothan Press Limited.

Dominick, R. J. (1996). The dynamics of mass communication (5th ed., pp. 32-53). USA: MCC Raw-Hall Companies, Inc.

Egbon, M. (1995). Social responsibility and the Nigerian mass media: Strategies and tactics for a balance media coverage of crisis. In A. R. Akinfeleye, S. Omole and O. Omang (Eds.), Mass media and national crisis (pp. 55-84). Lagos: Nigerian Press Council.

Federal Ministry of Education (FME). (2007). Special Teacher Upgrading Programme: NCE course Book 1 on education (p. 380). Kaduna: National Teachers' Institute.

Houghton, M. H. (2016). The role and influence of mass media. Retrieved 2018, from https://www.quora.com/what-is-the-relationship-between-the-media-and-society

Ike, G. A. (2006). The concept and process of communication. In A. O. Iwu, G. A. Ike and O. S. Chimezie (Eds.), Perspective on educational technology (pp. 107-108). Owerri: Peace Publishers Limited.

Njemanze, O. U., \& Ononiwu, M. C. (2015). The role of the media in the teaching and development of English language in Nigeria. Retrieved 2017, from http://www.assweb.com/journals/5019

Onwuka, U. (1996). Curriculum: An inevitable aspect of education. In U. Onwuka (Ed.), Curriculum development for Africa. Onitcha: Africana-Fep Publishers Limited.

Onyejemezi, D. A. (1996). Curriculum materials. In U. Onwuka (Ed.), Curriculum development for Africa (p. 447). Onitsha: Africana-Fep Pubishers Limited.

Owuamanam, C. N. (2016). The importance of mass media in developing and promoting Nigerian languages. A Journal of the National Institute for Nigerian Languages, 3(1), 287-296.

Schneider, D. K. (2015). Educational technology. Retrieved 2018, from http://edutechwiki-unigech/en/educationaltechnology

Selwyn, N. (2011). Education and technology. Retrieved 2018, from http://edutechwiki-unigech/en/educationaltechnology

Twitter. (2016). Interpersonal communication skill. Retrieved 2018, from http://www.skillyouneed.com/ips/barriers-communi cation.htm

Wikipedia, (2016). Educational technology. Retrieved 2019, from https://wiki educator.org/meaning-and-scope-of-educationaltechnology

Yaaka. (2017). Instructional communication system and development. Retrieved from https://www.yaaka.cc/unit/instructionalcommunication-system-and-development/test 